occurring within, and between, the tracks. Dr. E. J. Hart and M. S. Matheson (Chicago) described experiments with continuous and intermittent $\gamma$-radiation on aqueous hydrogen peroxide solutions in paraffin-coated cells, in which they found that the decomposition yield depended on the square root of the hydrogen peroxide concentration and inversely on the square root of the dosage-rate. A novel feature of the mechanism proposed was that chain termination results from the termolecular reaction $2 \mathrm{HO}_{2} \rightarrow$ $\mathrm{H}_{2} \mathrm{O}_{2}+\mathrm{O}_{2}$, in which hydrogen peroxide is regarded as being a third body of exceptionally high efficiency. Dr. M. Ebert and J. W. Boag (London) reported experiments on the decomposition of water and hydrogen peroxide by electrons and $\mathrm{X}$-rays, showing that with neutral water there is no dependence on the intensity of the radiation, but that in acid solution the equilibrium concentration of hydrogen peroxide produced by large doses depends on the intensity. The mechanism proposed received some confirmation by further work on hydrogen peroxide produced in neutral aerated water by 30 and $220 \mathrm{kV}$. X-rays and $1 \cdot 2 \mathrm{MeV}$. electrons by these workers in collaboration with Dr. M. Lefort (Paris and Leeds), H. C. Sutton (Leeds) and M. Ebert and Tikvah Alper (Hammersmith) using different analytical techniques. Dr. T. J. Hardwick (Chalk River) showed that, in the indirect action of $\mathrm{X}$ - and $\gamma$-radiation on aqueous ferrous and ceric sulphates, the yield varies with the initial energy of the ionizing electrons, and that this effect may be explained on the basis of existing theories of the primary action of ionizing radiation on water. The probability of the recombination of hydrogen atoms and of hydroxyl radicals was calculated as a function of the instantaneous electron energy.

Dr. E. Collinson and Prof. Dainton (Leeds) showed that the kinetics of the polymerization of aqueous acrylonitrile solutions induced by $X$ - and $\gamma$-rays are strongly different from photochemical or catalysed reactions, and are consistent with an inhomogeneous distribution of the radicals formed from water, while at higher dose-rates an increasing degree of homogeneity is indicated. The three types of radiation used produced the same results. In heavy water $\left(\mathrm{D}_{2} \mathrm{O}\right)$ solution irradiation leads to the formation of deuterium atoms which participate in the polymerization. In the discussion it was suggested that the unusual kinetics might in part be due to the insolubility of polymer in monomer.

The remaining papers dealt with more complex systems : Dr. G. Stein (Jerusalem) described the reactions of certain dyes in aqueous and non-aqueous systems, drew comparisons with biological systems and then discussed the role of the hydroxyl radical, free electrons and molecular oxygen in the radiation chemistry of organic substrates. Tikvah Alper (Hammersmith) reported experiments on the indirect inactivation of bacteriophage by ionizing radiations, and gave survival curves under various conditions. Dr. W. M. Dale (Manchester) discussed the possible protective effect of a second solute which may act as a competitive acceptor of free radicals, and the use of this effect, which is specific, as a measure of the protective power of various solutes. Dr. C. B. Allsopp and J. Wilson (London) showed that the quantity of indole decomposed in aqueous solution by $\mathrm{X}$-rays increases with increasing concentration of indole and with decreasing dosage-rate. The radiation and the photochemical decompositions follow similar courses. Dr. W. Minder and H. Heydrich (Berne) discussed the results of their experiments on the irradiation of halogenated hydrocarbons in organic solvents, which show that the formation of halogen acids depends on the dose, the concentration of the solution, the number of halogen atoms in the compound and the type of binding.

The meeting was very successful on both the scientific and social sides, and may fulfil the hope expressed by Sir Charles Goodeve at the guest-night dinner that it would stimulate the development of radiation chemistry as much as a previous discussion many years ago had that of the closely related subject of photochemistry. The papers, together with discussion on them submitted in writing to the secretary, will appear later as a separate publication of the Faraday Society.

J. W. Belton

\section{SCIENTIFIC EDUCATION OF PHYSICISTS}

$T$

HE pamphlet "The Scientific Education of Physicists"*, recently issued by the Institute of Physics, is a report prepared by the Education Committee of the Institute which should act as a useful guide, for students who wish to enter the profession of physics and for those who have the responsibility of advising or teaching such students, to the facilities available for the education and training of physicists.

The Institute recognizes only two qualifications as satisfying completely the academic requirements for election to corporate membership-an approved degree from a recognized university, and the Institute's own graduateship examination-although partial exemption from the graduateship examination may be claimed by those who have previously obtained the Higher National Certificate in applied physics. In addition to the suitable degree courses at university institutions, the report refers to the several technical colleges which provide advanced courses in physics, usually for the external degree of the University of London, but it warns the intending student that very often such technical colleges, with the exception of the London Polytechnics and a few of the main provincial colleges, have poor facilities for teaching physics and very rarely do their resources extend to an honours course in physics. Moreover, since he will find it extremely difficult to obtain adequate financial assistance at a technical college, for the student who wishes to continue and do postgraduate research, usually leading to the M.Sc. or Ph.D. degrees, it is almost essential that he should study at a university institution. However, many of the major technical, as well as university, Institutions do run excellent part-time courses, series of lectures and summer schools on advanced topies in physics which practising physicists will find of great value.

The report emphasizes the importance to the science student of an ability to express himself clearly, concisely and easily in English, both in speech and in writing. Recent discussion in the press has not settled whether the admitted prevalence of a low standard in English among physics students is due to lack of attention at the school or at higher levels; but in the report it is attributed mainly to individual negligence. The report concludes with appendixes giving factual data relating to the individual physics departments of all the universities and university * The Scientific Education of Physicists. Pp. 32. (London : Institute of Physics, 1952.) 28 . 
colleges of Great Britain and Northern Ireland and of those technical colleges recognized by the Institute. As most universities are now revising their regulations, the information given in the report should be treated with some caution. It is always wise for the intending student to make early and direct application to the university institution or college concerned and to obtain the most up-to-date information. It would have been a good thing if some such indication had been added to the report.

\section{POSTERIOR PITUITARY GLAND SYMPOSIUM AT CAMBRIDGE}

A

VERY informative session took place in the Physiological Laboratory, Cambridge, on June 20, when the Society for Endocrinology held a symposium on the posterior pituitary gland. This meeting was unique in the sense that so many of the speakers had made substantial contributions to our knowledge concerning this gland, and that so much more overall information is available for the posterior pituitary than any other endocrine gland.

The control of the secretion of the antidiuretic hormone was discussed from two different points of view. Dr. P. A. Jewell and Prof. E. B. Verney gave an account of their recent work dealing with the localization of the osmoreceptors. Intracarotid injection of hypertonic sodium chloride solution inhibits water diuresis by causing release of the antidiuretic hormone. However, the exact site of the receptor elements (osmoreceptors) stimulated by this hypertonic solution is not known for certain. Anatomical investigation of the vascular bed of the internal carotid artery showed that this vessel supplies the pituitary gland, the anterior hypothalamus including the greater part of the supraoptic and paraventricular nuclei, as well as other parts of the prosencephalon. Proof was given that the osmoreceptors do not lie in the pars nervosa of the pituitary. The findings in an animal in which an internal carotid artery had been tied intradurally suggest that the receptors lie in the prosencephalon. Dr. Mary Pickford emphasized that the supraoptic nerve cells, that give rise to the majority of nerve fibres which supply the posterior pituitary, can be activated by different types of stimuli, some arriving by nervous pathways, some being directly chemical, and some being physical or physico-chemical. She described the release of antidiuretic hormone from the posterior pituitary gland following injection of acetylcholine, nicotine, morphine and ferritin. Acetylcholine is rendered temporarily ineffective in this respect after application of diisopropylfluorophosphonate to the supraoptic nuclei. Intracarotid injection of adrenaline given prior to an antidiuretic dose of acetylcholine regularly annuls the action of the latter. It is of much interest that morphine is still effective in inhibiting a high rate of urine flow if applied directly to the supraoptic nerve cells, whether or not the cholinesterase of the cells of the supraoptic nuclei have been inactivated by disopropylfuorophosphonate.

Prof. H. B. van Dyke, of the Department of Pharmacology, College of Physicians and Surgeons, Columbia University, then dealt with the subject of posterior pituitary extracts. Ten years ago van Dyke, Chow, Greep and Rothen ${ }^{1}$ extracted a protein from the pars nervosa of the pituitary with the biological activities of both (antidiuretic - pressor and oxytocic) principles in about the same ratio as they are found in the gland. Its molecular weight was found to be about thirty thousand, and its biological activity was found to be low (1 unit $=61 \mu \mathrm{gm}$.). Although considerable evidence has been obtained that oxytocic and antidiuretic activities are present in constant ratios and that the protein is homogeneous, the possibility of adsorption of highly active principles on to an inert protein molecule has not been excluded. The highly purified principles recently isolated by du Vigneaud and his co-workers were discussed by Prof. van $\mathrm{Dyke}^{2-5}$. These principles have been isolated in a highly active form, 1 unit of the oxytocic principle being contained in $1 \cdot 25 \mu \mathrm{gm}$. and 1 unit of the antidiuretic-vasopressor principle in $1.6 \mu \mathrm{gm}$. The amino-acid content of these two principles has been investigated, and it has been found that tyrosine, cystine, aspartic acid, glutamic acid, glycine and proline are common to both, whereas arginine and phenylalanine characterize the oxytocic principle and leucine and isoleucine characterize the antidiuretic vasopressor principle. Using these principles, various workers have established that neither the contraction of the isolated rat uterus nor the ejection of milk by the lactating mammary gland is a specific test for the oxytocic principle, whereas the depressor response of the fowl's blood pressure appears to meet this requirement provided that contamination by antidiureticvasopressor principle is not excessive. The extremely sensitive antidiuretic test in the dog was found to be specific for the antidiuretic - vasopressor principle. It is not yet possible to decide from the published investigations whether the neurohypophysis secretes a large molecule containing both oxytocic and antidiuretic - vasopressor principles, or smaller molecules of highly active principles. The separate secretion of the latter has more teleological attraction.

In the next contribution, Prof. $\mathrm{H}$. Heller dealt with the fate of the posterior pituitary (antidiuretic) hormone when secreted into the blood. Previous work had shown that antidiuretic extracts are rapidly inactivated by defibrinated blood, serum and liver homogenate. When injected intravenously the antidiuretic activity of posterior pituitary extracts disappears rapidly from the circulating blood, and antidiuretic activity appears in the urine. Recent unpublished experiments of Ginsburg and Heller have shown that the liver and kidney both play a part in the 'clearance' of the antidiuretic principle : it would seem that, in addition to excreting it, the kidney also removes it by another, as yet unknown, process. The question of the renal excretion of the antidiuretic principle, both of endogenous and of exogenous origin, was discussed in further detail.

B. A. Cross described the evidence underlying the present concept of a milk ejection reflex ${ }^{6-8}$. It can now be taken as established that the act of suckling stimulates a nervous reflex excitation of the posterior pituitary gland, and the secretion from this gland causes contraction of some element of the mammary gland and thus a positive ejection of milk from the mother to the young. Recent work using du Vigneaud's highly active oxytocic and antidiuretic extracts indicates that the posterior pituitary principle underlying milk ejection is the oxytocic principle and not a mixture of the two, as had been previously suggested. Mr. Cross also discussed unpublished work in which it was found that previous administration of adrenaline, or electrical stimulation of the posterior region of the hypothalamus with 